\title{
Immigrants' mental health service use compared to that of native Finns: a register study
}

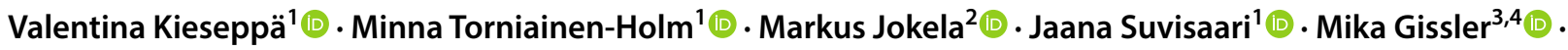 \\ Niina Markkula ${ }^{5}$ (D) Venla Lehti ${ }^{5}$ (D)
}

Received: 28 March 2019 / Accepted: 3 September 2019 / Published online: 21 September 2019

(C) The Author(s) 2019

\begin{abstract}
Purpose Many aspects related to migration might predispose immigrants to mental health problems. Yet immigrants have been shown to underuse mental health services. The aim of this study was to compare the intensity of psychiatric care, as an indicator of treatment adequacy, between natives and immigrants living in Finland.

Methods We used nationwide register data that included all the immigrants living in Finland at the end of 2010 $(n=185,605)$ and their matched controls. Only those who had used mental health services were included in the analyses $(n=14,285)$. We used multinomial logistic regression to predict the categorized treatment intensity by immigrant status, region and country of origin, length of residence, and other background variables.

Results Immigrants used mental health services less than Finnish controls and with lower intensity. The length of residence in Finland increased the probability of higher treatment intensity. Immigrants from Eastern Europe, sub-Saharan Africa, the Middle East, and Northern Africa were at the highest risk of receiving low-intensity treatment.

Conclusions Some immigrant groups seem to persistently receive less psychiatric treatment than Finnish-born controls. Identification of these groups is important and future research is needed to determine the mechanisms behind these patterns.
\end{abstract}

Keywords Immigrants $\cdot$ Mental health care $\cdot$ Treatment access $\cdot$ Register study

Electronic supplementary material The online version of this article (https://doi.org/10.1007/s00127-019-01774-y) contains supplementary material, which is available to authorized users.

\section{Valentina Kieseppä}

valentina.kieseppa@helsinki.fi

1 Mental Health Unit, National Institute for Health and Welfare, P.O. Box 30, 00271 Helsinki, Finland

2 Department of Psychology and Logopedics, Medicum, University of Helsinki, P.O. Box 63, 00014 Helsinki, Finland

3 Information Services Department, National Institute for Health and Welfare, P.O. Box 30, 00271 Helsinki, Finland

4 Department of Neurobiology, Care Sciences and Society, Karolinska Institute, 17177 Stockholm, Sweden

5 Department of Psychiatry, Helsinki University Hospital and University of Helsinki, P.O. Box 100, 00029 Helsinki, Finland

\section{Introduction}

Immigration into western countries is a growing phenomenon [1]. At the end of $2017,6.8 \%$ of the Finnish population was born in other countries than Finland [2]. The reasons behind this migration include work and marriage, but migration also happens due to poor living conditions in the country of origin, where immigrants have often experienced war or violence. Many aspects related to migration may predispose immigrants to mental health problems: separation from one's family, linguistic and cultural differences, possible hostile or racist attitudes in the host country, and possible traumatic events in the country of origin [3].

Studies have indeed indicated that immigrants, especially refugees, have a greater risk of developing some mental illnesses than native populations [1, 3-6]. In many countries, psychotic disorders, mood disorders, and post-traumatic stress disorders have been more common among immigrants than native populations [3-5, 7].

Recent Finnish register studies, based on the same data used here, have found that the incidence of most diagnosed 
psychiatric disorders was lower among immigrants than native Finns [8], and that immigrants had overall lower mortality; they especially died less often of alcohol-related causes and suicides [9]. Post-traumatic stress disorder was the only disorder for which immigrants had a higher risk than native Finns [8]. These contradictory findings were hypothesized to be at least partly related to the generally worse mental health in Finland as compared to other Nordic countries, for example higher suicide mortality and higher level of alcohol consumption [10]. Another potential reason for this is the "healthy migrant"-effect. Some selection plays a role prior to migration: healthier individuals are more likely to be able to migrate, which leads migrants to be overall healthier than native populations. Healthy migrant effect has been documented in many countries, although it does seem to wear off in time [11-13]. Considering mental health, evidence of healthy migrant effect is, however, controversial [14].

It has been repeatedly found in many European and North American studies that immigrants are less likely to use mental health services compared to natives [1, 15-19]. Findings have varied regarding the type of service used, ethnic groups, and the reason for migration. A typical finding is that immigrants are less likely to use outpatient care [15, $16,18,20]$. On the other hand, risks for inpatient care, compulsory care, and coercive treatment have been found to be higher among immigrants compared to natives [21-23]. In Switzerland, the risk of inpatient admission was significantly higher for immigrant men but generally lower for immigrant women [24]. In the Netherlands, immigrants used more outpatient care compared to natives but, when adjusted for need, immigrants seemed underrepresented [16]. Some studies have found that immigrants from refugee-generating countries have a higher use of services while labor immigrants use services less [18, 25]. Differences in use have also been reported between different ethnic groups [16, 18, 22, 26]. In Finland, Kurdish-, Somali-, and Russian-origin immigrants' mental health service use has been studied in the "Migrant Health and Wellbeing Study (Maamu)" [27]. Immigrants from Somalia and immigrant women from Russia reported using services less than the general population while Kurdish immigrant women reported using services more. There were no differences between the groups in the purchase of psychiatric medication, excepting immigrant women from Somalia who purchased psychiatric medication less than the general Finnish population [28].

In contrast to service use in general, only few previous studies have measured the intensity of treatment. A Canadian population-based study measured intensity as the number of visits in mental health services during 5 years after arrival, and they found that the intensity of treatment was lower among immigrants as compared to long-term residents [19]. An Australian case-control study compared the number visits in mental health services, length of hospital treatments and longest period without treatment between visits, and found no differences between Australian-born and immigrants [29]. An Italian case-control study focusing on patients of a specific psychiatric clinic examined the treatment intensity as the length of treatment and number of visits, which did not differ between native Italians and immigrants [30]. However, immigrants dropped out from treatment more often than natives. Many studies, including previous research in Finland, have relied on self-reporting $[16,20,26,27,31]$ or only concentrated on some immigrant groups [16, 26, 27, 31-33].

Finland has comprehensive public health care with universal health coverage [10] and visits in outpatient mental health services are usually free of charge. The municipalities are responsible for organizing public health care and all residents are covered by it [34]. Health services are divided into primary health care and specialized medical care, and to the latter patients are usually referred by a general practitioner or an occupational physician. Public services are used much more than private ones, especially for severe mental health problems. However, mental health services for immigrants have been criticized for large regional differences both in availability and in quality [35].

Overall, previous research on the intensity of psychiatric treatment in different immigrant groups compared with the native population is scarce. Moreover, the Finnish context, where the proportion of the total population with a migrant background is still relatively small, may differ from many other countries. Therefore, we set out to compare the intensity of mental health treatment with specialized mental health care between immigrants and native Finns, and to investigate how the region and country of origin, and the length of residence in Finland affected the intensity of psychiatric treatment.

\section{Materials and methods}

"The Mental Health of Immigrants Living in Finland" study uses a register-based sample maintained by the National Institute for Health and Welfare (THL). The study utilizes Finnish registers to study the prevalence of visits to mental health care services of both immigrants and native Finns. The THL, the Finnish Central Population Register (FCPR), and Statistics Finland have given their permissions for the use of confidential register data in this study, and it has been approved by the Ethics Committee of the THL in Finland $(589 / 2013)$. 


\section{Sample}

Immigrants were identified from the FCPR by country of birth and mother tongue, as described in detail elsewhere [8, 9]. The original sample includes all immigrants who were over 15 years old and residents in Finland on December 31st, $2010(n=185,605)$ and Finnish-born controls $(n=185,605)$. The sample does not include asylum seekers or undocumented migrants since they do not have a valid personal identity code, which is necessary for the data linkages. The controls were matched by sex and age so that they were born in the same year and month as the migrant and matched by the municipality of residence on December 31st, 2010. Both cases and controls were followed until death, emigration, or December 31st, 2015.

For the present study, we selected persons (immigrants and natives) with at least one visit to specialized mental health outpatient care or at least one hospital stay in psychiatric inpatient care who had had no prior psychiatric treatment in the preceding 2 years before the follow-up period. This 2-year wash-out period was chosen to ensure that our sample would only include incident cases as we wanted to study the psychiatric treatment provided directly after the patient had sought help for an incident condition. The follow-up started at the first visit to psychiatric services and extended over the following 12 months. As we had the information on visits to psychiatric services from 2007 to 2015 and the information on background variables from 2011 to 2015, the first visit had to be between the beginning of 2011 and the end of 2014 so that both the 2-year wash-out period and the 1-year study period could be applied. The final sample included 6059 (42.4\%) immigrants and 8226 (57.6\%) Finnish controls. Only this sample is used in the analyses.

\section{Background characteristics}

The background characteristics of interest included age, sex, marital status, socioeconomic status, country of origin, and length of residence in Finland. Information on socioeconomic status was derived from Statistics Finland [36] and information on the other variables was derived from the FCPR. Age at the beginning of the study was used both as a continuous and categorized variable. The categories were: (1) 15-29, (2) 30-44, (3) 45-59, and (4) 60 years or more. Marital status was classified into two groups: (1) married or in a registered partnership and (2) another status (single, divorced, separated, or cohabiting without marriage/registered partnership). Socioeconomic status was based on the occupation (or lack thereof) in 2010 and, in this study, it was classified into five groups: (1) entrepreneurs and farmers, (2) upper white-collar workers (such as leaders or experts), and (3) lower white-collar workers (such as office workers), (4) blue-collar workers (manual work), and (5) another status (people not in employment, such as students, unemployed, homemakers, etc.). Region of origin was classified into five groups: (1) EU/European Free Trade Association (EFTA), North America, and Australia, (2) Eastern Europe (including Russia and the former Soviet Union), (3) the Middle East and Northern Africa, (4) Sub-Saharan Africa, and (5) Asia. The number of immigrants from other countries was so small that no separate category was formed for them and they were thus excluded in the analyses related to region of origin. We also specifically studied the countries with over 100 individuals in the final sample (Estonia, Germany, Sweden, the UK, the USA, Russia and the former Soviet Union, the former Yugoslavia, Afghanistan, Iraq, Iran, Turkey, Somalia, and Thailand). Length of residence in Finland at the beginning of the study was classified into three groups: (1) less than 5 years, (2) 5-15 years, and (3) more than 15 years.

\section{Psychiatric treatment}

Information on visits to psychiatric services (2007-2015) was obtained from the Hospital Discharge Register, which covers hospital inpatient care and outpatient care in specialized services. The register is maintained by the THL. We studied the treatment patterns for 1 year after the patients had sought treatment. Since the number of visits to psychiatric care (one hospital stay in psychiatric inpatient care was counted as one visit) ranged from 1 to 302 , but most had very few visits $($ mean $=9$, median $=4$, mode $=1)$, we categorized the number of visits as follows: (1) one to three visits: low intensity ( $n=6707)$; (2) four to ten visits: moderate intensity ( $n=3678)$; and (3) over ten visits: high intensity $(n=3900)$. Since the high-intensity group was strongly left skewed $($ mean $=24$, median $=19$, mode $=11)$, we studied this group further. There was a small group with extensive use (more than 52 visits a year; $n=178$ ).

Having made less than 4 visits most likely indicates a short consultation; while having over ten visits suggested that the treatment included comprehensive evaluation and psychosocial support.

\section{Statistical analysis}

Standard statistical methods were used to calculate descriptive statistics. Chi square tests of independence were calculated to compare differences in background variables between immigrants and controls. An independent samples $t$ test was conducted to compare the difference in mean age between immigrants and controls.

Multinomial logistic regression analysis was used to study the effect of immigrant status, length of residence in Finland, region of origin, and other background characteristics on the categorized intensity of the treatment variable. 
In the first model, the main interest was the association between immigrant status and the intensity of psychiatric treatment. Covariates included age, sex, marital status, and socioeconomic status. Interactions between immigrant status and other variables were also tested to examine whether the associations of the covariates with treatment were different among immigrants and Finnish-born controls. Nonsignificant interactions were removed from the analysis. The reference category for the outcome variable was highintensity visits (over 10 visits) in all the models. The second regression model included only immigrants. We were interested in whether the length of residence in Finland and the region of origin predicted the intensity of treatment. For the length of residence variable, " 15 years or more" was used as a reference category. For the country of origin variable, the reference category was "EU/EFTA, North America, and Australia," because this group probably resembles the Finnish population the most. In the third model, we studied the differences between 14 countries of origin regarding the intensity of treatment. Finnish controls were chosen as the reference group. We used a level of significance of $P<0.05$. Analyses were carried out using IBM SPSS Statistics 25.

\section{Results}

The descriptive statistics are presented in Table 1. There were more incidents of psychiatric treatment contact among Finnish controls $(n=8226)$ than among immigrants $(n=6059)$. Compared to Finnish service users, immigrants were slightly older [mean age $36.7(\mathrm{SD}=13.4)$ vs. 35.5 $(\mathrm{SD}=12.7), t(14,283)=5.418, P<0.001]$ and more likely to be married or in a registered partnership [40.6 vs. $25.8 \%$, $\left.\chi^{2}(1)=498.172, P<0.001\right]$. Socioeconomic status also varied significantly $\left[\chi^{2}(4)=320.564, P<0.001\right]$ : Finnish-born controls were more likely to be upper white-collar workers (9.5 vs. $5.9 \%)$ and lower white-collar workers (22.6 vs. $12.0 \%)$ than immigrants while immigrants were more likely to be blue-collar workers (17.9 vs. $15.9 \%)$ and in the another status category than the Finnish-born controls (47.8 vs. $41.3 \%$ ). Information on marital status was missing for 467 immigrants (7.7\%) and information on socioeconomic status was missing for 545 Finnish-born controls (6.6\%) and 681 immigrants (11.2\%).

A slightly higher percentage of the immigrants had at least one hospital stay compared to controls (20.4 vs. $19.5 \%)$, but the difference was not statistically significant $\left[\chi^{2}(1)=1.890, P=0.169\right]$. The immigrants had less intensive treatments: $50.5 \%$ of the immigrants received treatment of low intensity (one to three visits) compared to $44.3 \%$ of the controls; $23.1 \%$ of the immigrants received treatment of high intensity (over 10 visits) compared to $30.4 \%$ of the controls. The majority of those with more than 52 visits a year were Finnish controls (71\%). This might reflect the higher percentage of substance-use disorders (substitution treatment might require "visits" every single day for long periods of time) and serious illnesses such as psychotic disorders among Finnish-born controls [8]. Additional information of the distribution of the background variables between
Table 1 Sample characteristics by immigrant status

\begin{tabular}{lcrr}
\hline & Controls & Immigrants & \multicolumn{1}{c}{$P$} \\
\hline Total $(n, \%)$ & $8226(57.6)$ & $6059(42.4)$ & $<\mathbf{0 . 0 0 1}$ \\
Age [mean (standard deviation)] & $35.5(12.7)$ & $36.7(13.4)$ & $<\mathbf{0 . 0 0 1}$ \\
Sex (male) $(n, \%)$ & $3654(44.4)$ & $2626(43.3)$ & 0.199 \\
Marital status (married/registered partnership) $(n, \%)$ & $2122(25.8)$ & $2461(40.6)$ & $<\mathbf{0 . 0 0 1}$ \\
SES ( $n, \%)$ & & & $<\mathbf{0 . 0 0 1}$ \\
(1) Entrepreneurs and farmers & $336(4.1)$ & $310(5.1)$ & \\
(2) Upper white-collar workers & $780(9.5)$ & $357(5.9)$ & \\
(3) Lower white-collar workers & $1863(22.6)$ & $726(12)$ & \\
(4) Blue-collar workers & $1306(15.9)$ & $1085(17.9)$ & \\
(5) Other & $3394(41.3)$ & $2896(47.8)$ & \\
Individuals with at least one hospital stay $(n, \%)$ & $1603(19.5)$ & $1237(20.4)$ & 0.169 \\
Intensity of treatment & & & $<\mathbf{0 . 0 0 1}$ \\
Low (1-3 visits) & $3645(44.3)$ & $3062(50.5)$ & \\
Moderate (4-10 visits) & $2079(25.3)$ & $1599(26.4)$ & \\
High (>10 visits) & $2502(30.4)$ & $1398(23.1)$ & \\
\hline
\end{tabular}

Only service users are included

Bold values indicate significance level of $P<0.05$

SES socioeconomic status 
treatment intensity categories can be found in Supplementary Table 1 (Online Resource).

Supplementary Tables 2 and 3 (Online Resource) show how the intensity of the treatment was distributed between different regions and countries of origin. Individuals from sub-Saharan Africa were the most likely to receive treatment of low intensity and the least likely to receive treatment of high intensity. The length of residence in Finland was related to more intensive treatments: among those who had lived in Finland less than 5 years, $51.7 \%$ received treatment of low intensity, but among those who had lived in Finland for over 15 years, only $46.8 \%$ received treatment of low intensity.

The results of the first regression model are presented in Table 2. Immigrants, compared to natives, were more likely to receive treatment of low intensity $(\mathrm{OR}=2.14$, $95 \% \mathrm{CI}=1.65-2.78, P<0.001)$ and treatment of moderate intensity $(\mathrm{OR}=1.60,95 \% \mathrm{CI}=1.19-2.14, P=0.002)$ when compared to the probability of treatment of high intensity. The likelihood of receiving treatment of low and moderate intensity was elevated by male sex $(\mathrm{OR}=1.29$, 95\% CI $=1.18-1.40, P<0.001$ and $\mathrm{OR}=1.15,95 \%$ $\mathrm{CI}=1.04-1.27, P=0.007$, respectively) and by older age $(\mathrm{OR}=1.02,95 \% \mathrm{CI}=1.02-1.03, P<0.001$ and $\mathrm{OR}=1.01$, $95 \% \mathrm{CI}=1.01-1.02, P<0.001$, respectively). Being in employment significantly decreased the risk of low-intensity treatment at all levels.

We also tested interaction effects between immigrant status and other variables. Only the interaction between age as a continuous variable and immigrant status was significant (included in the model 1). To detect a possible nonlinear interaction, we squared age and added the quadratic age variable and the interaction term between squared age and immigrant status in the model. The interaction effect between

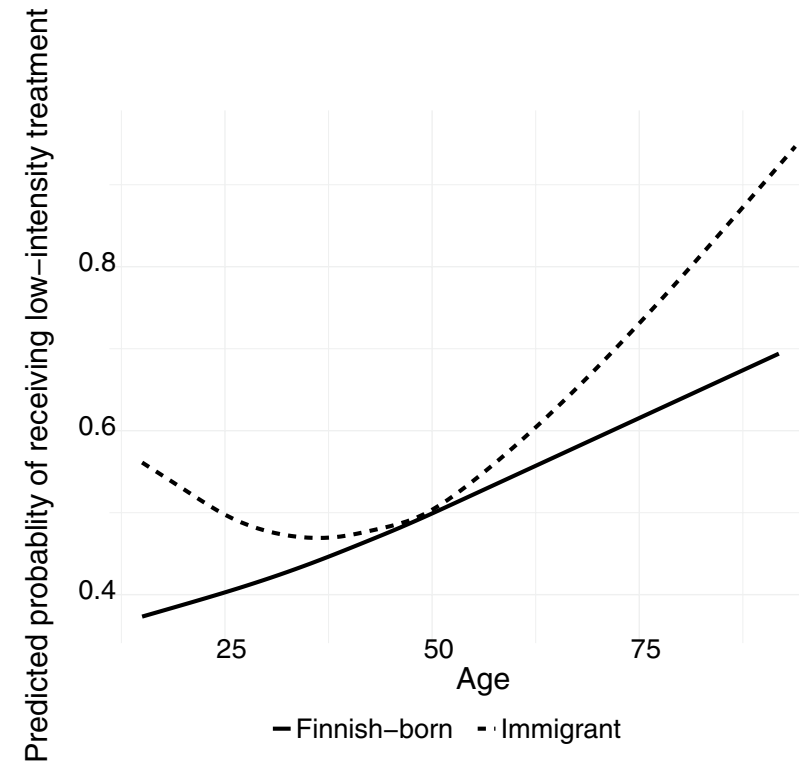

Fig. 1 Interaction between age and immigrant status

age and immigrant status was significant $(\mathrm{OR}=0.93,95 \%$ $\mathrm{CI}=0.90-0.96, P<0.001)$ as was the interaction between squared age variable and immigrant status $(\mathrm{OR}=1.001,95 \%$ $\mathrm{CI}=1.000-1.001, P=0.001)$. The results indicate that the effect of age was quadratic for immigrants and linear for Finnish-born controls (Fig. 1). The mean predicted probability of low-intensity treatment was the lowest among immigrants aged from 30 to 59 years (48-49\%) but slightly higher among immigrants aged from 15 to 29 years $(50.9 \%)$, even higher among immigrants aged from 15 to 19 years (53.9\%), and the highest among immigrants over $60(72.6 \%)$.
Table 2 Immigrant status as a predictor for treatment intensity

\begin{tabular}{|c|c|c|c|c|}
\hline & \multicolumn{4}{|c|}{ Intensity of treatment } \\
\hline & \multicolumn{2}{|l|}{ Low } & \multicolumn{2}{|l|}{ Moderate } \\
\hline & OR $(95 \% \mathrm{CI})$ & $P$ & OR $(95 \% \mathrm{CI})$ & $P$ \\
\hline Immigrant (ref. Finnish) & $2.14(1.65-2.78)$ & $<0.001$ & $1.60(1.19-2.14)$ & 0.002 \\
\hline Age & $1.02(1.02-1.03)$ & $<0.001$ & $1.01(1.01-1.02)$ & $<0.001$ \\
\hline Male (ref. Female) & $1.29(1.18-1.40)$ & $<0.001$ & $1.15(1.04-1.27)$ & 0.007 \\
\hline $\begin{array}{l}\text { Married/registered partnership } \\
\text { (reff. Others) }\end{array}$ & $0.94(0.85-1.03)$ & 0.196 & $0.99(0.89-1.11)$ & 0.884 \\
\hline \multicolumn{5}{|l|}{ SES (ref. Others) } \\
\hline Entrepreneurs and farmers & $0.78(0.64-0.95)$ & 0.014 & $0.84(0.67-1.05)$ & 0.13 \\
\hline Upper white-collar workers & $0.74(0.63-0.86)$ & $<0.001$ & $0.80(0.67-0.95)$ & 0.01 \\
\hline Lower white-collar workers & $0.74(0.66-0.83)$ & $<0.001$ & $0.84(0.74-0.95)$ & 0.007 \\
\hline Blue-collar workers & $0.85(0.75-0.95)$ & 0.006 & $0.89(0.78-1.01)$ & 0.074 \\
\hline Immigrant status $\times$ age & $0.99(0.98-0.996)$ & 0.002 & $1.00(0.99-1.00)$ & 0.18 \\
\hline
\end{tabular}

Reference group for the outcome variable is "High intensity". Only service users are included Bold values indicate significance level of $P<0.05$ 
Table 3 Length of residence and region of origin as predictors for treatment intensity

\begin{tabular}{|c|c|c|c|c|}
\hline & \multicolumn{4}{|c|}{ Intensity of treatment } \\
\hline & \multicolumn{2}{|l|}{ Low } & \multicolumn{2}{|l|}{ Moderate } \\
\hline & OR (95\% CI) & $P$ & OR $(95 \% \mathrm{CI})$ & $P$ \\
\hline \multicolumn{5}{|c|}{ Length of residence (ref. $>15$ years) } \\
\hline$<5$ years & $1.55(1.29-1.85)$ & $<0.001$ & $1.38(1.13-1.70)$ & 0.002 \\
\hline $5-15$ years & $1.44(1.22-1.70)$ & $<0.001$ & $1.29(1.07-1.56)$ & 0.007 \\
\hline \multicolumn{5}{|c|}{ Region of origin (ref. EU/EFTA, North America, Australia) } \\
\hline Eastern Europe & $1.32(1.11-1.58)$ & 0.002 & $1.14(0.93-1.39)$ & 0.197 \\
\hline $\begin{array}{l}\text { Middle East and Northern } \\
\text { Africa }\end{array}$ & $1.24(1.03-1.49)$ & 0.026 & $1.17(0.95-1.44)$ & 0.148 \\
\hline Sub-Saharan Africa & $1.46(1.11-1.92)$ & 0.007 & $1.33(0.98-1.80)$ & 0.072 \\
\hline Asia & $1.02(0.80-1.29)$ & 0.905 & $0.71(0.53-0.94)$ & $\mathbf{0 . 0 1 7}$ \\
\hline Male (ref. female) & $1.33(1.16-1.53)$ & $<0.001$ & $1.11(0.95-1.30)$ & 0.187 \\
\hline \multicolumn{5}{|l|}{ Age (ref. > 60 years) } \\
\hline $15-29$ & $0.26(0.16-0.42)$ & $<0.001$ & $0.60(0.33-1.09)$ & 0.094 \\
\hline $30-44$ & $0.24(0.15-0.40)$ & $<0.001$ & $0.68(0.38-1.23)$ & 0.205 \\
\hline $45-59$ & $0.27(0.16-0.45)$ & $<0.001$ & $0.78(0.43-1-41)$ & 0.407 \\
\hline
\end{tabular}

Only immigrants who used services are included in the model. Reference group for the outcome variable is "High intensity"

Bold values indicate significance level of $P<0.05$
For Finnish controls, older age predicted lower treatment intensity.

The results of the second model, which included only immigrants, are presented in Table 3 . The model is adjusted for age and sex as they were the strongest covariates in the first model. Age was used as a categorized variable because of its nonlinear effect. The longer the patients had lived in Finland, the more likely they were to receive treatment of high intensity. Immigrants from Eastern Europe, sub-Saharan Africa, the Middle East, and Northern Africa were more likely to receive treatment of low intensity than those from EU/EFTA, North America, or Australia. The difference was most elevated among immigrants from Sub-Saharan Africa (OR=1.46, 95\% CI =1.11-1.92, $P=0.007)$.

In the third model (Table 4 ), we predicted the intensity of treatment with the country of origin, adjusted for age and sex. The likelihood of treatment of low intensity was higher among all immigrant groups compared to natives, except for those from the UK and the USA, although the difference was not statistically significant for those from Germany, Yugoslavia and Turkey. The highest likelihood of treatment of low intensity was among those from Somalia, Iraq, and Afghanistan who were all over twice as likely to receive treatment of low intensity compared to Finnish-born controls. The likelihood of treatment of moderate intensity was elevated among all except those from the UK, although the difference was statistically significant only for those born in Sweden, Russia and the former Soviet Union, Afghanistan, Iraq, and Somalia.

\section{Discussion}

In Finland, where health care services are available and universally accessible to all residents, we found that even when immigrants use mental health services, which they do less often than natives [8], they do so with lower treatment intensity compared to natives. This is in line with prior research [15-19] and complements the prior results as regarding to the treatment intensity [19, 29, 30]. The longer the immigrants had lived in Finland, the more likely they were to receive treatment of high intensity: in other words, their profiles of treatment patterns started to resemble those of the Finnish-born natives more closely the longer they had lived in Finland. This is in line with previous research [22, 32]. The region of origin analysis showed that those from Eastern Europe, sub-Saharan Africa, the Middle East, and Northern Africa were most likely to receive treatment of low intensity: over half of them received only one to three visits of mental health treatment after seeking help.

In the analysis of specific countries of origin, those from Somalia, Iraq, and Afghanistan had an especially high risk of low treatment intensity. Our results are in contrast with studies from Norway $[18,32]$ that have reported immigrants from Iraq to have higher use compared to natives. Immigrants from Somalia seem to persistently use mental health services less than natives and other immigrants [18, $22,33]$. Some studies have indicated that immigrants from refugee-generating countries generally use more services than natives $[18,25,33]$. We did not have the information 
Table 4 Country of origin as a predictor for treatment intensity

\begin{tabular}{|c|c|c|c|c|}
\hline & \multicolumn{4}{|c|}{ Intensity of treatment } \\
\hline & \multicolumn{2}{|l|}{ Low } & \multicolumn{2}{|l|}{ Moderate } \\
\hline & OR $(95 \% \mathrm{CI})$ & $P$ & OR $(95 \% \mathrm{CI})$ & $P$ \\
\hline \multicolumn{5}{|l|}{ Country of origin (ref. Finland) } \\
\hline \multicolumn{5}{|c|}{ EU/EFTA, North America, Australia } \\
\hline Estonia & $1.39(1.13-1.70)$ & 0.001 & $1.24(0.99-1.56)$ & 0.064 \\
\hline Germany & $1.61(0.99-2.62)$ & 0.057 & $1.41(0.81-2.46)$ & 0.227 \\
\hline Sweden & $1.93(1.41-2.65)$ & $<0.001$ & $2.02(1.44-2.85)$ & $<0.001$ \\
\hline UK & $0.94(0.60-1.48)$ & 0.799 & $0.83(0.48-1.41)$ & 0.484 \\
\hline USA & $0.86(0.53-1.41)$ & 0.549 & $1.40(0.84-2.31)$ & 0.196 \\
\hline \multicolumn{5}{|l|}{ Eastern Europe } \\
\hline Russia and Soviet Union & $1.65(1.43-1.91)$ & $<0.001$ & $1.49(1.26-1.76)$ & $<0.001$ \\
\hline Yugoslavia & $1.36(1.00-1.86)$ & 0.052 & $1.34(0.95-1.90)$ & 0.098 \\
\hline \multicolumn{5}{|c|}{ Middle East and Northern Africa } \\
\hline Afghanistan & $2.53(1.74-3.67)$ & $<0.001$ & $2.53(1.69-3.78)$ & $<0.001$ \\
\hline Iraq & $2.17(1.67-2.82)$ & $<0.001$ & $2.29(1.73-3.04)$ & $<0.001$ \\
\hline Iran & $1.47(1.09-1.97)$ & 0.012 & $1.26(0.90-1.77)$ & 0.181 \\
\hline Turkey & $1.14(0.80-1.63)$ & 0.48 & $1.10(0.73-1.65)$ & 0.66 \\
\hline \multicolumn{5}{|l|}{ Sub-Saharan Africa } \\
\hline Somalia & $2.21(1.51-3.24) 2$ & $<0.001$ & $1.82(1.19-2.80)$ & 0.006 \\
\hline \multicolumn{5}{|l|}{ Asia } \\
\hline Thailand & $1.58(1.05-2.39)$ & 0.029 & $1.06(0.65-1.75)$ & 0.808 \\
\hline Male (ref. female) & $1.38(1.26-1.50)$ & $<0.001$ & $1.17(1.06-1.29)$ & 0.002 \\
\hline \multicolumn{5}{|l|}{ Age (ref. > 60 years) } \\
\hline $15-29$ & $0.30(0.32-0.39)$ & $<0.001$ & $0.59(0.44-0.81)$ & 0.001 \\
\hline $30-44$ & $0.37(0.28-0.48)$ & $<0.001$ & $0.67(0.50-0.92)$ & 0.012 \\
\hline $45-59$ & $0.42(0.32-0.55)$ & $<0.001$ & $0.76(0.55-1.04)$ & 0.082 \\
\hline
\end{tabular}

Reference group for the outcome variable is "High intensity". Only service users are included in the model Bold values indicate significance level of $P<0.05$ on the reason for migration so we cannot draw direct conclusions, but in contrast with previous findings, it seems that immigrants from areas with more refugee migration were most likely to receive treatment of low intensity.

As expected, male sex was related to lower treatment intensity for both immigrants and natives [37]. Older age (60 years old or more) was related to less intensive treatments for both immigrants and natives. In addition, immigrants in the youngest age group (aged 15-29 years) seemed to be slightly more at risk for low-intensity treatments compared to immigrants of the age groups from 30 to 59 years. A similar pattern did not appear for Finnish controls, for whom the effect of age was linear. Socioeconomic status predicted treatment intensity: those not in employment were more likely to receive treatment of low intensity. Previously, low income has been linked to a greater unmet need for mental health treatment [38] although there have been conflicting findings [39].

\section{What causes the disparities in mental health care use?}

One explanation for the observed disparities is of course simply a lack of need for mental health services due to better psychological health. This might be at least partly due to the "healthy migrant effect" [11, 13]. A Finnish register study, based on the same data used here, showed that while immigrants generally presented better mental health compared to native Finns, the highest incidence of any diagnosed mental disorders were among those from Northern Africa and the Middle East and this group also had the highest incidence of depressive disorders [8]. Other Finnish studies have also shown that immigrants of Kurdish origin (the majority from Iraq) [27] and immigrants from the Middle East and Northern Africa [40] suffer from more self-reported psychiatric symptoms than the general Finnish population. According to international studies, immigrants from refugee-generating countries have an increased risk of some psychiatric symptoms [41]. In light of this, it seems unlikely that the 
disparities could be explained purely by the lack of a need for treatment.

A second explanation for the differences is unwillingness to use mental health services, for example, because of fear of stigma [42,43] or because religious or spiritual help is preferred $[44,45]$ to Western health care. In previous studies from Finland, older Somali immigrants have been found to prefer religious experts' help for mental issues [45] and to rather use somatic services than mental services for mental problems [46], which might explain their low-intensity treatments. A Canadian study investigated the reasons behind immigrants' reluctance to use Western mental health care services. They found that psychiatric medication in particular was often seen as a strange solution to mental problems and, behind the negative attitudes, there were often negatively perceived encounters with other physicians, and sometimes nonmedical, often religious help was preferred [44]. In Finland, purchasing psychiatric medication has not been found to differ between immigrants and natives [28].

Third, the disparities might be explained by structures, such as cultural, linguistic, or financial barriers [20, 31]. In Finland, cost should not be an issue since service use is mainly free of charge, although we did find an association between not being in employment and lower treatment intensity. In international studies, communicational issues have been shown to be common [47], and while just getting an interpreter might be hard, it has been reported that immigrant patients might not feel understood even while they use an interpreter [48]. The bureaucratic health care service system might be difficult to use and health care locations can be hard to find.

Practical difficulties might also explain disparities within age groups; immigrants in the youngest age group are more likely to have arrived in Finland relatively recently and to still be unfamiliar with the Finnish health care system. It is concerning that immigrants received less intensive treatment at adolescence and young adulthood, a critical life stage for identity formation, separation from childhood family and decisions about education and career where mental disorders have been shown to have a long-lasting effect on, e.g., the educational outcomes and the quality of life [49].

Some immigrant groups seem to be underrepresented in mental health care, and this disparity most likely reflects at least some barriers to mental health care. The reasons behind these disparities should be addressed in future studies. Possible structures that act as barriers to mental health care use for immigrants should be identified to develop mental health services that have more cultural and structural competence to address the needs of the immigrant population.

\section{Strengths and limitations}

Our study has several strengths. Our nationwide data covered the entire immigrant population (apart from asylum seekers and undocumented migrants), and thereby there is almost no selection bias. The hospital discharge register, which was used to attain the information on mental health care use, is highly reliable [50] and covers all public specialized mental health care use. In addition, our study addressed specifically immigrants from 14 countries, thus gaining information of the mental health care use of both almost the entire immigrant population and specific ethnic groups.

There are also limitations associated with register-based studies. The most obvious limitation is the lack of information on the perceived need for mental health services, which limits us from making further conclusions about the mechanisms behind the observed patterns. Second, we only had information on the use of the mental health services of the public sector, thereby we excluded those who use private services instead. However, there are no private mental hospitals in Finland and private services are used much less than public ones. For example, there were 561 mental health outpatient visits per 1000 persons aged 18 years and over in the whole country but only 24 visits per 1000 persons to private psychiatrists in year 2017 [51]. It is also presumable that the general Finnish population uses private services more than those immigrants who had the lowest treatment intensity (immigrants from Eastern Europe, Sub-Saharan Africa and Middle East and Northern Africa). Third, our study did not include asylum seekers or undocumented migrants, who together form a group that is particularly vulnerable to mental problems. Fourth, we did not exclude those who emigrated during the follow-up, and it is possible that not all subjects lived in Finland for a full year after their first contact, thereby making it impossible for them to have been receiving mental health care in Finland. Finally, because of the mental health differences of the Finnish-born as compared to other Nordic countries, generalization of the results to other countries should be done carefully.

In conclusion, immigrants use mental health services less, as has already been shown [8], and with lower frequency compared to native Finns. This disparity most likely reflects (at least partly) cultural barriers to care. Differences were most marked among immigrants from Eastern Europe, subSaharan Africa, the Middle East, and Northern Africa. In the analysis of specific countries of origin, immigrants from Somalia, Iraq and Afghanistan were particularly at risk of treatment of low intensity. These findings are alarming as these immigrant groups are in many ways the most vulnerable and are at risk of having had traumatic experiences in their past. Further research is needed to investigate the mechanisms behind these patterns. 
Acknowledgements Open access funding provided by National Institute for Health and Welfare (THL). Marjut Grainger is acknowledged for data management. This work was supported by grants from The Social Insurance Institution of Finland (Kela; Dnro 36/26/2018) and Otto A. Malm Foundation.

\section{Compliance with ethical standards}

Conflict of interest On behalf of all the authors, the corresponding author states that there is no conflict of interest.

Open Access This article is distributed under the terms of the Creative Commons Attribution 4.0 International License (http://creativeco mmons.org/licenses/by/4.0/), which permits unrestricted use, distribution, and reproduction in any medium, provided you give appropriate credit to the original author(s) and the source, provide a link to the Creative Commons license, and indicate if changes were made.

\section{References}

1. Lindert J, Schouler-Ocak M, Heinz A, Priebe S (2008) Mental health, health care utilisation of migrants in Europe. Eur Psychiatry 23:14-20. https://doi.org/10.1016/S0924-9338(08)70057-9

2. Suomen virallinen tilasto [SVT]: Väestörakenne [verkkojulkaisu]. ISSN $=1797-5379$. Helsinki: Tilastokeskus. http://www.stat.fi/til/ vaerak/index.html. Accessed Jan 72019

3. Bhugra D, Jones P (2001) Migration and mental illness. Adv Psychiatr Treat 7(3):216-222. https://doi.org/10.1192/apt.7.3.216

4. Bourque F, van der Ven E, Malla A (2011) A meta-analysis of the risk for psychotic disorders among first- and second-generation immigrants. Psychol Med 41(5):897-910. https://doi.org/10.1017/ S0033291710001406

5. Mindlis I, Boffetta P (2017) Mood disorders in first- and secondgeneration immigrants: systematic review and meta-analysis. Br J Psychiatry 210(3):182-189. https://doi.org/10.1192/bjp. bp. 116.181107

6. Bas-Sarmiento P, Saucedo-Moreno MJ, Fernández-Gutiérrez M, Poza-Méndez M (2017) Mental health in immigrants versus native population: a systematic review of the literature. Arc Psychiatr Nurs 31(1):111-121. https://doi.org/10.1016/j.apnu.2016.07.014

7. Dykxhoorn J, Kirkbride JB (2018) Psychoses sans frontieres: towards an interdisciplinary understanding of psychosis risk amongst migrants and their descendants. Epidemiol Psych Sci 28(2):146-152. https://doi.org/10.1017/S2045796018000501

8. Markkula N, Lehti V, Gissler M, Suvisaari J (2017) Incidence and prevalence of mental disorders among immigrants and native Finns: a register-based study. Soc Psychiatry Psychiatr Epidemiol 52(12):1523-1540. https://doi.org/10.1007/s00127-017-1432-7

9. Lehti V, Gissler M, Markkula N, Suvisaari J (2017) Mortality and causes of death among the migrant population of Finland in 201113. Eur J Public Health 27(1):117-123. https://doi.org/10.1093/ eurpub/ckw196

10. GBD 2016 SDG Collaborators (2017) Measuring progress and projecting attainment on the basis of past trends of the healthrelated sustainable development goals in 188 countries: an analysis from the global burden of disease study 2016. Lancet 390(10100):1423-1459. https://doi.org/10.1016/S0140 $-6736(17) 32336-X$

11. McDonald JT, Kennedy S (2004) Insights into the "healthy immigrant effect': health status and health service use of immigrants to
Canada. Soc Sci Med 59(8):1613-1627. https://doi.org/10.1016/j. socscimed.2004.02.004

12. Moullan Y, Jusot F (2014) Why is the "healthy immigrant effect" different between European countries? Eur J Public Health 24(suppl 1):80-86. https://doi.org/10.1093/eurpub/cku112

13. Helgesson $M$, Johansson $B$, Nordquist T, Vingård E, Svartengren M (2019) Healthy migrant effect in the Swedish context: a register-based, longitudinal cohort study. BMJ Open 9(3):e026972. https://doi.org/10.1136/bmjopen-2018-026972

14. Lee R (2019) Does the healthy immigrant effect apply to mental health? Examining the effects of immigrant generation and racial and ethnic background among Australian adults. SSM Popul Health. https://doi.org/10.1016/j.ssmph.2018.10.011

15. Derr AS (2016) Mental health service use among immigrants in the United States: a systematic review. Psychiatr Serv 67(3):265274. https://doi.org/10.1176/appi.ps.201500004

16. Koopmans G, Uiters E, Devillé W, Foets M (2013) The use of outpatient mental health care services of migrants vis-à-vis Dutch natives: equal access? Int J Soc Psychiatry 59(4):342-350. https ://doi.org/10.1177/0020764012437129

17. Berg JE (2009) The level of non-western immigrants' use of acute psychiatric care compared with ethnic Norwegians over an 8-year period. Nord J Psychiatry 63(3):217-222. https://doi. org/10.1080/08039480802571010

18. Abebe DS, Lien L, Elstad JI (2017) Immigrants' utilization of specialist mental healthcare according to age, country of origin, and migration history: a nation-wide register study in Norway. Soc Psychiatry Psychiatr Epidemiol 52(6):679-687. https://doi. org/10.1007/s00127-017-1381-1

19. Durbin A, Lin E, Moineddin R, Steele LS, Glazier RH (2014) Use of mental health care for nonpsychotic conditions by immigrants in different admission classes and by refugees in Ontario, Canada. Open Med 8(4):e136-e146

20. Lee S, Matejkowski J (2012) Mental health service utilization among noncitizens in the United States: findings from the National Latino and Asian American Study. Adm Policy Ment Health 39(5):406-418. https://doi.org/10.1007/s10488-011-0366-8

21. Knutzen M, Sandvik L, Hauff E, Opjordsmoen S, Friis S (2007) Association between patients' gender, age and immigrant background and use of restraint-a 2-year retrospective study at a department of emergency psychiatry. Nord J Psychiatry 61(3):201-206. https://doi.org/10.1080/08039480701352520

22. Manhica H, Almquist Y, Rostila M, Hjern A (2017) The use of psychiatric services by young adults who came to Sweden as teenage refugees: a national cohort study. Epidemiol Psychiatr Sci 26(5):526-534. https://doi.org/10.1017/S2045796016000445

23. Mulder CL, Koopmans GT, Selten J-P (2007) Emergency psychiatry, compulsory admissions and clinical presentation among immigrants to the Netherlands. Br J Psychiatry 188(4):386-391. https://doi.org/10.1192/bjp.188.4.386

24. Lay B, Nordt C, Rössler W (2007) Mental hospital admission rates of immigrants in Switzerland. Soc Psychiatry and Psychiatr Epidemiol 42(3):229-236. https://doi.org/10.1007/s0012 7-007-0157-4

25. Nielsen SS, Jensen NK, Kreiner S, Norredam M, Krasnik A (2015) Utilisation of psychiatrists and psychologists in private practice among non-Western labour immigrants, immigrants from refugee-generating countries and ethnic Danes: the role of mental health status. Soc Psychiatry Psychiatr Epidemiol 50(1):67-76. https://doi.org/10.1007/s00127-014-0916-y

26. Gerritsen AAM, Bramsen I, Devillé W, van Willigen LHM, Hovens JE, van der Ploeg HM (2006) Use of health care services by Afghan, Iranian, and Somali refugees and asylum seekers living in The Netherlands. Eur J Public Health 16(4):394-399. https:// doi.org/10.1093/eurpub/ck1046 
27. Castaneda A, Rask S, Koponen P, Mölsä M, Koskinen S (2012) Maahanmuuttajien terveys ja hyvinvointi. Tutkimus venäläis-, somalialais- ja kurditaustaisista Suomessa. [Migrant health and wellbeing. A study on persons of Russian, Somali and Kurdish origin in Finland]. National Institute for Health and Welfare [THL], Helsinki

28. Koponen P, Rask S, Skogberg N, Castaneda A, Manderbacka K, Suvisaari J, Kuusio H, Laatikainen T, Keskimäki I, Koskinen S (2016) Suomessa vakituisesti asuvat maahanmuuttajat käyttävät vaihtelevasti terveyspalveluja. Suomen lääkärilehti 71(12-13):907-914

29. Klimidis S, McKenzie DP, Lewis J, Minas IH (2000) Continuity of contact with psychiatric services: immigrant and Australian-born patients. Soc Psychiatry and Psychiatr Epidemiol 35(12):554-563. https://doi.org/10.1007/s001270050279

30. Gramaglia C, Gambaro E, Rossi A, Toso A, Feggi A, Cattaneo CI, Castignoli G, Mainini P, Tarricone I, Torre E, Zeppegno P (2016) Immigrants' pathways to outpatient mental health: are there differences with the native population? J Immigr Minor Health 18(4):878-885. https://doi.org/10.1007/s10903-015-0336-4

31. Kirmayer LJ, Weinfeld M, Burgos G, du Fort GG, Lasry J-C, Young A (2007) Use of health care services for psychological distress by immigrants in an urban multicultural Milieu. Can J Psychiatry 52(5):295-304. https://doi.org/10.1177/0706743707 05200504

32. Straiton M, Reneflot A, Diaz E (2014) Immigrants' use of primary health care services for mental health problems. BMC Health Serv Res 14:341. https://doi.org/10.1186/1472-6963-14-341

33. Straiton ML, Reneflot A, Diaz E (2017) Mental health of refugees and non-refugees from war-conflict countries: data from primary healthcare services and the norwegian prescription database. $\mathrm{J}$ Immigr Minor Health 19(3):582-589. https://doi.org/10.1007/ s10903-016-0450-y

34. Sadeniemi M, Almeda N, Salinas-Pérez JA, Gutiérrez-Colosía MR, García-Alonso C, Ala-Nikkola T, Joffe G, Pirkola S, Wahlbeck K, Cid J, Salvador-Carulla L (2018) A comparison of mental health care systems in Northern and Southern Europe: a service mapping study. Int $\mathrm{J}$ of Environ Res Public Health 15(6):1133. https://doi.org/10.3390/ijerph15061133

35. Rauta A. (2005) Selvitys maahanmuuttajien mielenterveyspalvelujen tarpeesta ja saatavuudesta. Sosiaali- ja terveysministeriön selvityksiä [Reports of the Ministry of Social Affairs and Health]: 3. Sosiaali- ja terveysministeriö, Helsinki

36. Statistics Finland (1989) Classification of socioeconomic groups. Handbooks 17. https://www.stat.fi/meta/luokitukset/sosioekon asema/001-1989/kasikirja.pdf. Accessed 13 Feb 2019

37. Wang PS, Aguilar-Gaxiola S, Alonso J et al (2007) Use of mental health services for anxiety, mood, and substance disorders in 17 countries in the WHO world mental health surveys. Lancet 370(9590):841-850. https://doi.org/10.1016/S0140 -6736(07)61414-7

38. Wang PS, Lane M, Olfson M, Pincus HA, Wells KB, Kessler RC (2005) 12-month use of mental health services in the United States: results from the national comorbidity survey replication. Arch Gen Psychiatry 62(6):629-640. https://doi.org/10.1001/ archpsyc.62.6.629
39. Roy-Byrne PP, Joesch JM, Wang PS, Kessler RC (2009) Low socioeconomic status and mental health care use among respondents with anxiety and depression in the NCS-R. Psychiatr Serv 60(9):1190-1197

40. Nieminen T, Sutela H, Hannula U (2015) Ulkomaista syntyperää olevien työ ja hyvinvointi Suomessa 2014. Tilastokeskus, Helsinki

41. Kirmayer LJ, Narasiah L, Munoz M, Rashid M, Ryder AG, Guzder J, Hassan G, Rousseau C, Pottie K (2011) Common mental health problems in immigrants and refugees: general approach in primary care. Can Med Assoc J 183(12):E959-E967. https:// doi.org/10.1503/cmaj.090292

42. Nadeem E, Lange JM, Edge D, Fongwa M, Belin T, Miranda J (2007) Does stigma keep poor young immigrant and U.S.born black and Latina women from seeking mental health care? Psychiatr Serv 58(12):1547-1554. https://doi.org/10.1176/ ps.2007.58.12.1547

43. Clement S, Schauman O, Graham T, Maggioni F, Evans-Lacko S, Bezborodovs N, Morgan C, Rüsch N, Brown JSL, Thornicroft $\mathrm{G}$ (2015) What is the impact of mental health-related stigma on help-seeking? A systematic review of quantitative and qualitative studies. Psychol Med 45(1):11-27. https://doi.org/10.1017/S0033 291714000129

44. Whitley R, Kirmayer LJ, Groleau D (2006) Understanding immigrants' reluctance to use mental health services: a Qualitative study from montreal. Can J Psychiatry 51(4):205-209. https:// doi.org/10.1177/070674370605100401

45. Mölsä M, Tiilikainen M, Punamäki R-L (2017) Usage of healthcare services and preference for mental healthcare among older Somali immigrants in Finland. Ethn Health 24(6):607-622. https ://doi.org/10.1080/13557858.2017.1346182

46. Schubert CC, Punamäki R-L, Suvisaari J, Koponen P, Castaneda A (2019) Trauma, psychosocial factors, and help-seeking in three immigrant groups in Finland. J Behav Health Serv Res 46(1):80 98. https://doi.org/10.1007/s11414-018-9587-X

47. Carta MG, Bernal M, Hardoy MC, Haro-Abad JM, The "Report on the Mental Health in Europe" working group (2005) Migration and mental health in Europe [the state of the mental health in Europe working group: appendix 1]. Clin Pract Epidemiol in Ment Health 1(1):13. https://doi.org/10.1186/1745-0179-1-13

48. Herrel N, Olevitch L, DuBois DK et al (2004) Somali refugee women speak out about their needs for care during pregnancy and delivery. J Midwifery Women's Health 49(4):345-349. https://doi. org/10.1016/j.jmwh.2004.02.008

49. Kasteenpohja T, Marttunen M, Aalto-Setälä T, Perälä J, Saarni SI, Suvisaari J (2018) Outcome of depressive and anxiety disorders among young adults: results from the Longitudinal Finnish Health 2011 Study. Nord J Psychiatry 72(3):205-213. https://doi. org/10.1080/08039488.2017.1418429

50. Sund R (2012) Quality of the Finnish hospital discharge register: a systematic review. Scand J Public Health 40(6):505-515. https ://doi.org/10.1177/1403494812456637

51. Tilasto-ja indikaattoripankki Sotkanet.fi. Terveyden ja hyvinvoinnin laitos. https://www.sotkanet.fi/sotkanet/fi/index. Accessed Feb 132019 